\title{
A COMPARISON OF INDUCED AND SPONTANEOUS GENE CONVERSION IN MITOTIC AND MEIOTIC CELLS OF SACCHAROMYCES CEREVISIAE*
}

by

\author{
HERSCHEL ROMAN \\ Department of Genetics, SK-50, University of Washington, \\ Seattle, Washington 98195
} Keywords: Associated reciprocal recombination, simultaneous conversion, hybrid DNA,
double-strand exchange

\section{INTRODUCTION}

This paper is a sequel to one published in these Communications (4). Its purpose is to explore the differences between spontaneous and induced gene conversion with reference to associated reciprocal recombination, with reference to the simultaneous conversion at loci other than the one at which conversion is detected by selection and with reference to other parameters that might permit a qualitative distinction between mitotic and meiotic conversion.

The reasons for pursuing these questions are found first in the fact that gene conversion occurs in, both mitotic and meiotic cells in Saccharomyces cerevisiae and therefore it is of interest to know whether the underlying mechanisms are the same in both cases. Second, it has been suggested (1) that simultaneous gene conversion in mitotic cells is the consequence of a single event, namely, the formation of a single length of hybrid DNA (heteroduplex) that may encompass distant markers that are therefore simultaneously affected. An alternative explanation is that simultaneous conversion is the result of smaller heteroduplexes occurring as separate events, each heteroduplex involving only closely linked markers. Third, gene conversion is relatively rare in mitotic cells, of the order of $10^{-5}$ at a given locus, and therefore most studies of mitotic conversion have used both selective methods and mutagens, the latter to enhance the frequency of conversion. The question arises whether induced conversion is similar to spontaneous conversion or if the two differ in some detectable qualitative feature.

\section{MATERIALS AND METHODS}

\subsection{Yeast strains}

The diploid strains used in these experiments and the disposition of the alleles on chromosome VII are as follows:

\footnotetext{
*This paper is dedicated to HeINZ HOLTER in celebration of his 80 th birthday
} 

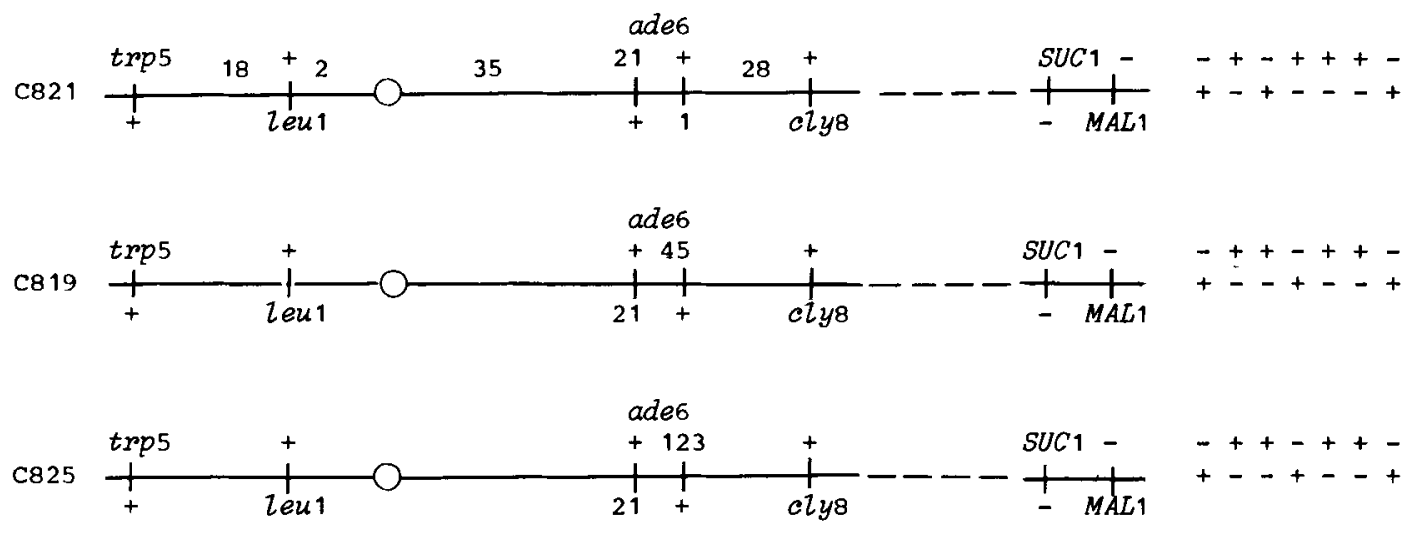

trp5, leu 1 and ade6 are recessive alleles that represent requirements for tryptophan, leucine and adenine, respectively; cly 8 is a recessive mutation that allows growth at $23^{\circ} \mathrm{C}$ and not at $35^{\circ} \mathrm{C}$. SUC 1 and $M A L 1$ are co-dominants for sucrose and maltose fermentation, respectively, and segregate as if they were alleles; their order, as given, is arbitrary. They do not show linkage with the proximal markers. The centromere is indicated by a circle between $l e u 1$ and ade 6 . The ade 6 alleles $21,1,45$ and 123 are in that order with respect to the centromere and to each other. The genotypes are represented as +'s and -'s in the right column.

\subsection{Treatment}

Stationary phase cells were sonicated and plated on adenineless synthetic medium, after being appropriately diluted. Cells were irradiated on the surface of the agar in open petri dishes. For X-rays, a dose of 3,000 rads was given

Table I.

Frequency of associated recombination of distal markers among induced and spontaneous $A D E 6$ prototrophs. Symbols under the columns "distal marker recombinants" represent homozygosis at the loci $C L Y 8, S U C 1$ and $M A L 1$. The 2:2 ratio indicates heterozygosity for $C L Y 8 \mathrm{cly} 8$. Refer to text for particulars.

\begin{tabular}{|c|c|c|c|c|c|c|c|c|c|c|c|c|}
\hline \multirow[b]{2}{*}{ Expt. } & \multirow{2}{*}{$\begin{array}{l}\text { Diploid } \\
\text { Culture }\end{array}$} & \multirow{2}{*}{ Treatment } & \multirow{2}{*}{$\begin{array}{l}\text { ADE6 } \\
\text { per } 10^{6}\end{array}$} & \multirow{2}{*}{$\begin{array}{l}\text { Prototrophs } \\
\text { Induced } / 10^{6}\end{array}$} & \multicolumn{5}{|c|}{ Distal Marker Recombinants } & \multirow[b]{2}{*}{ Total } & \multirow{2}{*}{$\begin{array}{r}\text { No. of } \\
\text { Cases }\end{array}$} & \multirow{2}{*}{$\begin{array}{c}\% \\
\text { Recomb. }\end{array}$} \\
\hline & & & & & ++- & --+ & +-+ & $2: 2+-$ & $2: 2-+$ & & & \\
\hline \multirow{2}{*}{\multicolumn{2}{|c|}{$78-1-4 \mathrm{C} 819$}} & $\mathrm{X}$-rays 0 & 8 & - & & & & & & & & \\
\hline & & 3000 rads & Is 349 & 341 & 4 & 2 & 0 & 1 & 1 & 8 & 68 & 24 \\
\hline \multirow{2}{*}{\multicolumn{2}{|c|}{$78-1-4 \mathrm{C} 825$}} & $\mathrm{X}$-rays 0 & 24 & - & & & & & & & & \\
\hline & & 3000 rads & s 854 & 30 & 0 & 7 & 0 & 0 & 2 & 9 & 70 & 26 \\
\hline \multirow{2}{*}{\multicolumn{2}{|c|}{$78-5-3 \mathrm{C} 821$}} & $\mathrm{X}$-rays 0 & 8 & - & & & & & & & & \\
\hline & & 3000 rads & s 790 & 782 & 5 & 5 & 0 & 3 & 1 & 14 & 104 & 27 \\
\hline \multirow{2}{*}{\multicolumn{2}{|c|}{$79-4-6 C 819$}} & UV $\quad 0$ & 10 & - & & & & & & & & \\
\hline & & $400 \frac{\mathrm{ergs}}{\mathrm{mm}^{2}}$ & $\frac{s}{a^{2}} 310$ & 300 & 2 & 7 & 0 & 0 & 1 & 10 & 112 & 18 \\
\hline \multirow{2}{*}{\multicolumn{2}{|c|}{$79-4-6$ C821 }} & UV $\quad 0$ & 19 & - & & & & & & & & \\
\hline & & $400 \frac{\mathrm{ergs}}{\mathrm{mm}^{2}}$ & $\frac{s}{n^{2}} 476$ & 457 & 10 & 3 & 0 & 1 & 0 & 14 & 115 & 24 \\
\hline \multirow{2}{*}{\multicolumn{2}{|c|}{$81-3-6 C 821$}} & EMS 0 & 24 & - & & & & & & & & \\
\hline & & $2 \mathrm{hr}$ & 326 & 302 & 6 & 1 & 0 & 0 & 0 & 0 & 109 & 14 \\
\hline $78-1-4$ & $\mathrm{C} 825$ & Spontaneous & & & 3 & 15 & 0 & 1 & 0 & 19 & 71 & 54 \\
\hline $78-5-3$ & $\mathrm{C} 821$ & Spontaneous & & & 13 & 7 & 0 & 0 & 2 & 22 & 99 & 44 \\
\hline $81-3-6$ & $\mathrm{C} 821$ & Spontaneous & & & 21 & 6 & 1 & 0 & 0 & 28 & 108 & 52 \\
\hline
\end{tabular}


Table II

Conversion in meiotic tetrads obtained from heteroallelic diploids in which conversion to $\mathrm{ADEF}^{+}$has occurred. The numbers above the line are in the order 3+:1- and 3-:1+, for the two classes of single-site conversion. The number below the line represents the total number of asci in each experiment in which detection of conversion at a given locus was possible. The "multiples" column represents cases of concomitant conversion at more than one locus.

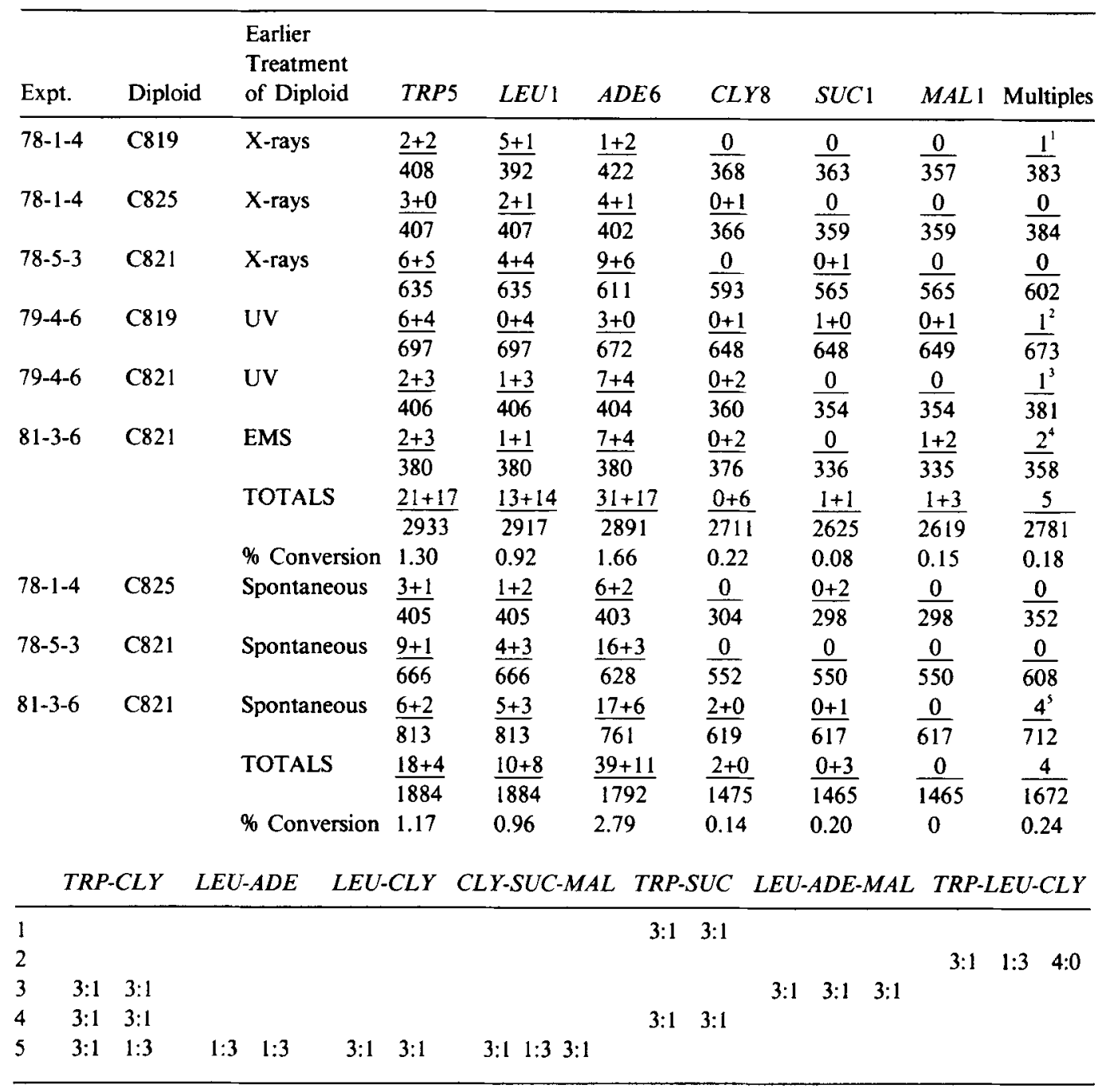

in all experiments, using a Machlett OEG 60 $\mathrm{X}$-ray tube operated at $50 \mathrm{kV}$ and $20 \mathrm{ma}$. The dose rate was approximately $100 \mathrm{rads} / \mathrm{sec}$. Irradiation with ultraviolet light utilized two $25 \mathrm{~W}$ Hanovia germicidal lamps, emitting 16 ergs/ $\mathrm{mm}^{2} / \mathrm{sec}$, as measured with a Latarjet dosimeter. A uniform dose of $400 \mathrm{ergs} / \mathrm{mm}^{2}$ was applied in all experiments with ultraviolet light. Precautions were taken to avoid photoreactivation. In the treatment with ethylmethane sulfonate (EMS), the cells were sonicated and $1 \mathrm{ml}\left(10^{8}\right.$ cells) added to a reaction vessel containing 0.2 $\mathrm{ml} \mathrm{EMS,} 8.8 \mathrm{ml}$ buffer ( $4 \%$ glucose in .2 M-phosphate buffer, $\mathrm{pH} 8.0$ ). The vessel was shaken at $30^{\circ} \mathrm{C}$ for 2 hours, a $.05 \mathrm{ml}$ aliquot was quenched with $4.95 \mathrm{ml}$ sodium thiosulfate for 10 minutes to neutralize any remaining EMS and was then plated, after appropriate dilution. 
Table III.

Conversion in meiotic tetrads obtained from C821. Data are extracted from Table II.

\begin{tabular}{|c|c|c|c|c|c|c|c|c|c|}
\hline Expt. & Diploid & $\begin{array}{l}\text { Treatment } \\
\text { of Diploid }\end{array}$ & TRP5 & $L E U 1$ & $A D E 6$ & $C L Y 8$ & $S U C 1$ & $M A L 1$ & Multiples \\
\hline \multirow[t]{2}{*}{$78-5-3$} & \multirow[t]{9}{*}{ C821 } & $\mathrm{X}$-rays & $\underline{6+5}$ & $\underline{4+4}$ & $\underline{9+6}$ & $\underline{0}$ & $\underline{0+1}$ & 0 & 0 \\
\hline & & & $\overline{635}$ & $\overline{635}$ & 611 & 593 & $\overline{565}$ & $\overline{565}$ & $\overline{602}$ \\
\hline \multirow[t]{2}{*}{$79-4-6$} & & UV & $\underline{2+3}$ & $\underline{1+3}$ & $\underline{7+4}$ & $\underline{0+2}$ & $\underline{0}$ & 0 & 1 \\
\hline & & & 406 & 406 & $\overline{404}$ & 360 & $\overline{354}$ & $\overline{354}$ & $\overline{381}$ \\
\hline \multirow[t]{5}{*}{$81-3-6$} & & EMS & $\underline{2+3}$ & $\underline{1+1}$ & $\underline{7+4}$ & $\underline{0+2}$ & 0 & $\underline{1+2}$ & 2 \\
\hline & & & 380 & 380 & 380 & 376 & 336 & 335 & 358 \\
\hline & & TOTALS & $\underline{10+11}$ & $\underline{6+8}$ & $\underline{23+14}$ & $\underline{0+4}$ & $\underline{0+1}$ & $\underline{1+2}$ & 3 \\
\hline & & & 1421 & 1421 & 1395 & $\overline{1329}$ & $\overline{1255}$ & $\overline{1254}$ & $\overline{1341}$ \\
\hline & & $\%$ Conversion & 1.48 & 0.99 & 2.65 & 0.30 & 0.08 & 0.24 & 0.22 \\
\hline \multirow[t]{2}{*}{$78-5-3$} & C821 & Spontaneous & $\underline{9+1}$ & $\underline{4+3}$ & $\underline{16+3}$ & 0 & $\underline{0+1}$ & 0 & $\underline{0}$ \\
\hline & & & $\overline{666}$ & $\overline{666}$ & $\overline{628}$ & $\overline{552}$ & $\overline{550}$ & $\overline{550}$ & $\overline{608}$ \\
\hline \multirow[t]{5}{*}{$81-3-6$} & & & $\underline{6+2}$ & $\underline{5+3}$ & $\underline{17+6}$ & $\underline{2+0}$ & $\underline{0+1}$ & 0 & 4 \\
\hline & & & $\overline{813}$ & $\overline{813}$ & $\overline{761}$ & $\overline{619}$ & $\overline{617}$ & $\overline{617}$ & $\overline{712}$ \\
\hline & & TOTALS & $\underline{15+3}$ & $9+6$ & $\underline{33+9}$ & $\underline{2+0}$ & $\underline{0+2}$ & $\underline{0}$ & 4 \\
\hline & & & $\overline{1479}$ & $\overline{1479}$ & $\overline{1389}$ & $\overline{1171}$ & $\overline{1167}$ & $\overline{1167}$ & $\overline{1320}$ \\
\hline & & $\%$ Conversion & 1.22 & 1.01 & 3.02 & 0.17 & 0.17 & 0 & 0.30 \\
\hline
\end{tabular}

\subsection{Media}

The growth and sporulation media were standard, as described by ROMAN and FABRE (5).

\section{RESULTS AND DISCUSSION}

The frequency of prototrophs induced by X-rays, ultraviolet light (UV) or ethylmethane sulfonate (EMS) is given in Table I. The background frequency of prototrophs in the culture before treatment is given for comparison with the treated frequency and is subtracted from the latter to obtain the induced frequency. The classes of associated recombinants for the distal markers, $C L Y 8, S U C 1$ and $M A L 1$, are also shown, as is the number of cases which were examined for recombination. The percent of associated recombination is calculated from these data and is multiplied by 2 to take into account the fact that only half of the recombinants are detected (4).

The spontaneous cases of conversion and associated recombination are also found in Table I. Independence of each spontaneous case was assured as follows: The untreated cultures in each experiment were plated on synthetic complete medium. The colonies on these plates after 3-4 days of incubation at $23^{\circ} \mathrm{C}$ were transferred to a grid on master plates containing yeast extract-peptone-glucose, allowed to resume growth for 2 days, and finally transferred by replica plating to adenineless plates. After several days, individual colonies began to appear against a background of no growth on the adenineless plates and one colony was sampled from each replica.

The results in Table I are noteworthy in two respects. One is a decided polarity of distal recombinants associated with conversion at the $A D E 6$ locus, in both the treated and spontaneous series. C821 gives a preponderance of ++recombinants whereas $\mathrm{C} 819$ and $\mathrm{C} 825$ have a preponderance of --+. The polarity is especially evident among spontaneous convertants. The difference is correlated with the orientation of the alleles at the $A D E 6$ locus, which is the same in $\mathrm{C} 819$ and $\mathrm{C} 825$ and is different in C821. Polarity implies reciprocal recombination between the two sites at the $A D E 6$ locus, an explanation that will be discussed later in this paper. Second, the frequency of associated recombination among the spontaneous cases in roughly $50 \%$ and is twice or more as high as is found in the induced series.

Asci obtained from the several experiments involving the three different heteroallelic combi- 
Table IV.

Recombination events in meiotic tetrads at $S U C 1$ and $M A L 1$ loci.

\begin{tabular}{|c|c|c|c|c|c|c|c|c|c|c|}
\hline \multirow[b]{6}{*}{ Expt. } & \multirow{6}{*}{$\begin{array}{l}\text { Diploid } \\
\text { Culture }\end{array}$} & \multirow{6}{*}{$\begin{array}{l}\text { Earlier } \\
\text { Treatment }\end{array}$} & \multicolumn{2}{|c|}{ Co-conversions } & \multirow{2}{*}{$\begin{array}{c}\begin{array}{c}\text { Reciprocal } \\
\text { Recombination }\end{array} \\
S U C M A L\end{array}$} & \multirow{4}{*}{\multicolumn{4}{|c|}{$\begin{array}{l}\text { Single-site } \\
\text { Conversion }\end{array}$}} & \multirow{6}{*}{$\begin{array}{l}\text { No. of } \\
\text { Asci }\end{array}$} \\
\hline & & & \multirow{5}{*}{$\begin{array}{c}M A L \\
- \\
- \\
- \\
+\end{array}$} & \multirow{5}{*}{$\begin{array}{cc}\text { SUC } & \text { MAL } \\
- & + \\
- & + \\
- & + \\
+ & -\end{array}$} & & & & & & \\
\hline & & & & & \multirow{3}{*}{$\begin{array}{l}+ \\
- \\
+\end{array}$} & & & & & \\
\hline & & & & & & & & & & \\
\hline & & & & & & \multicolumn{2}{|c|}{$S U C$} & \multicolumn{2}{|c|}{$M A L$} & \\
\hline & & & & & $\begin{array}{l}+ \\
- \\
+ \\
+\end{array}$ & $3: 1$ & $1: 3$ & $3: 1$ & $1: 3$ & \\
\hline $78-1-4$ & $\mathrm{C} 819$ & $\mathrm{X}$-rays & 0 & 0 & 1 & 0 & 0 & 0 & 0 & 363 \\
\hline $78-1-4$ & C825 & X-rays & 0 & 0 & 0 & 2 & 0 & 0 & 0 & 359 \\
\hline $78-5-3$ & C821 & $\mathrm{X}$-rays & 3 & 0 & 0 & 1 & 0 & 0 & 0 & 565 \\
\hline $79-4-6$ & C819 & UV & 0 & 0 & 1 & 0 & 1 & 0 & 0 & 648 \\
\hline $79-4-6$ & C821 & UV & 0 & 0 & 0 & 0 & 0 & 0 & 0 & 354 \\
\hline $81-3-6$ & C821 & EMS & 0 & 2 & 0 & 0 & 0 & 1 & 1 & 335 \\
\hline $78-1-4$ & $\mathrm{C} 825$ & Spont & 1 & 0 & 5 & 1 & 0 & 0 & 0 & 298 \\
\hline $78-5-3$ & C821 & Spont & 1 & 1 & 0 & 1 & 0 & 0 & 0 & 550 \\
\hline \multirow[t]{3}{*}{$81-3-6$} & C821 & Spont & 0 & 2 & 0 & 1 & 0 & 0 & 0 & 617 \\
\hline & & TOTALS & 5 & 5 & 7 & 6 & 1 & 1 & 1 & 4089 \\
\hline & & $\%$ & 0.12 & 0.12 & 0.17 & 0.1 & & 0.0 & & \\
\hline
\end{tabular}

nations were analyzed and classified for conversion. The results are shown in Table II. The type of treatment indicated in the third column of this table was given to the diploid cells many generations prior to sporulation and only serves as a guide to the history of the diploid culture. It is evident that those combinations that had a history of treatment do not give frequencies of conversion that are statistically different from those obtained from diploids that were not treated (see also Table III, in which only the results from C821 are given to avoid irregularities due to the influences of genotypic variation). Three points should be mentioned in assessing the contents of Table II. The first is that parity, the equivalence of the $3: 1$ and $1: 3$ classes of conversion does not always obtain. The deviations from parity for TRP5 and ADE6 are striking among spontaneous convertants but are less extreme or absent among induced convertants. Second, it is clear that conversion occurs more frequently at $A D E 6$ than at other loci. Third, the data in the last column in Table II shows that concomitant conversion has occurred at more than one locus. The centromere does not appear to be a barrier to coincidence.
Since the loci involved are generally some distance apart, as much as 100 centimorgans or more, it is likely that these are separate events.

If the interpretation of coincidence of conversion in meiosis is correct, there is no reason to assume that coincidental conversion does not have the same explanation when it occurs in mitosis (5). An alternative explanation for the coincidence of mitotic conversion can be found in ESPOSITO and WAGSTAFF (1).

Another type of irregular segregation, first observed by FoGEL and MORTIMER (2) is found at the fermentation loci $S U C 1$ and $M A L 1$ (Table IV). The fourth and fifth columns of this table provide evidence for co-conversion, an event that is interpreted to indicate that a single heteroduplex has been formed that includes these loci with resulting mismatch repair of the intact strand. It follows that the two genes are very near each other, if indeed they are not alleles. Table IV also provides evidence of reciprocal recombination between $S U C 1$ and $M A L 1$ and single-site conversion at the two loci.

A significant proportion of mitotic recombinants among $A D E 6$ prototrophs carries an allele that is mutant at both sites in the heteroallelic 
Table V.

Number of $++/--$ cases found among induced and spontaneous recombination at $A D E 6$ locus and an analysis of reciprocal recombination and single-site conversion in meiotic tetrads obtained from these cases.

\begin{tabular}{|c|c|c|c|c|c|c|c|}
\hline Expt. & Diploid & Treatment & $\begin{array}{l}\text { No. of } \\
++/-- \\
\text { Cases }\end{array}$ & $\begin{array}{l}\text { Total } \\
\text { No. of } \\
\text { Cases }\end{array}$ & $\begin{array}{l}\text { No. of } \\
\text { Tetrads }\end{array}$ & $\begin{array}{l}\text { Reciprocal } \\
\text { Recombination }\end{array}$ & $\begin{array}{l}\text { Single } \\
\text { Site } \\
\text { Conversion }\end{array}$ \\
\hline $78-1-4$ & C819 & $\mathrm{X}$-rays & 0 & 56 & 6 & 0 & 0 \\
\hline $78-1-4$ & C825 & $X$-rays & 8 & 59 & 42 & 2 & 2 \\
\hline $78-5-3$ & C821 & $X$-rays & 2 & 88 & 10 & 0 & 1 \\
\hline $79-4-6$ & C 819 & UV & 4 & 92 & 20 & 0 & 1 \\
\hline $79-4-6$ & C821 & UV & 3 & 98 & 10 & 1 & 0 \\
\hline $81-3-6$ & C82I & EMS & 0 & 68 & 0 & 0 & 0 \\
\hline $78-1-4$ & C825 & Spont & 9 & 52 & 53 & 5 & 4 \\
\hline $78-5-3$ & C821 & Spont & 6 & 78 & 28 & 1 & 1 \\
\hline \multirow[t]{3}{*}{$81-3-6$} & C821 & Spont & 3 & 81 & 34 & 5 & 3 \\
\hline & & TOTAL & 35 & 672 & 203 & 14 & 12 \\
\hline & & $\%$ & $\begin{array}{c}5.2 \\
(35 / 672)\end{array}$ & & & $\begin{array}{c}6.9 \\
(14 / 203)\end{array}$ & $\begin{array}{c}5.9 \\
(12 / 203)\end{array}$ \\
\hline
\end{tabular}

diploid (Table V). This $++/--$ class comprises approximately $8 \%$ of spontaneous $A D E 6$ prototrophs and is obtained also among induced prototrophs, the frequency apparently depending on the heteroallelic diploid and the inducing agent. Meiotic tetrads from these prototrophs were of six kinds. The expected 2:2 segregation for the ++ and - - alleles was found most frequently, in about $85 \%$ of the tetrads. The rest were about equally divided between those exhibiting reciprocal recombination and those that were single-site conversions, either $3: 1$ or $1: 3$, at one or the other of the two sites.
The details of the types of recombinant tetrads from this class are given in Table VI. The reciprocal recombinant class, $++/+-/-+/--$, follows a pattern in relation to the segregation of the $C L Y 8 / c l y 8$ pair of alleles that suggests reciprocal double-strand breakage between the two sites in $A D E 6$ (Table VII). The CLY 8 locus is the only distal locus useful for this analysis because it is the only one that shows linkage to $A D E 6$. In two of the seven tetrads from $\mathrm{C} 821$, the + - segregant was $c l y 8$ and the - + segregant was $C L Y 8$, as would be expected from a crossover between the two sites in $A D E 6$. In another,

Table VI.

The details of tetrads reported in Table $\mathrm{V}$.

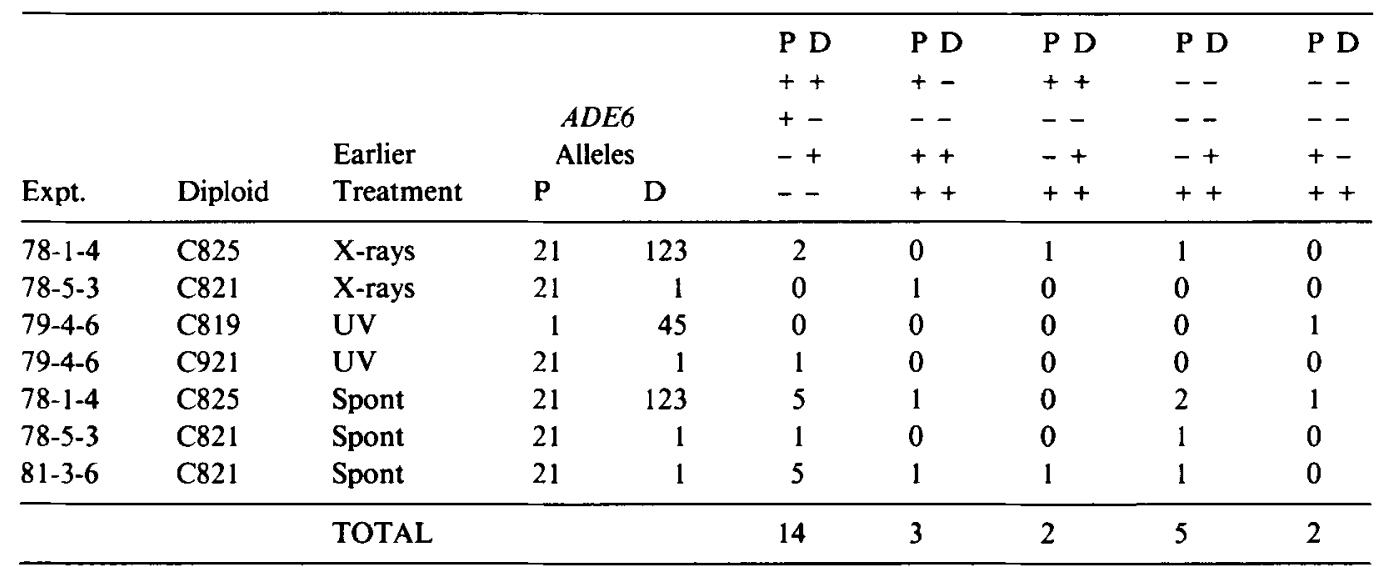


Table VII.

Associated recombination of distal markers in reciprocally recombinant tetrads from $++/--$ cases. The numbers 1, 2, 3, 4 and 5 represent, in that order, the two sites at the $A D E 6$ locus, the CLY8 locus and the SUC1 and $M A L 1$ loci. The latter are not given in those cases where their relation to the proximal markers is indeterminant.

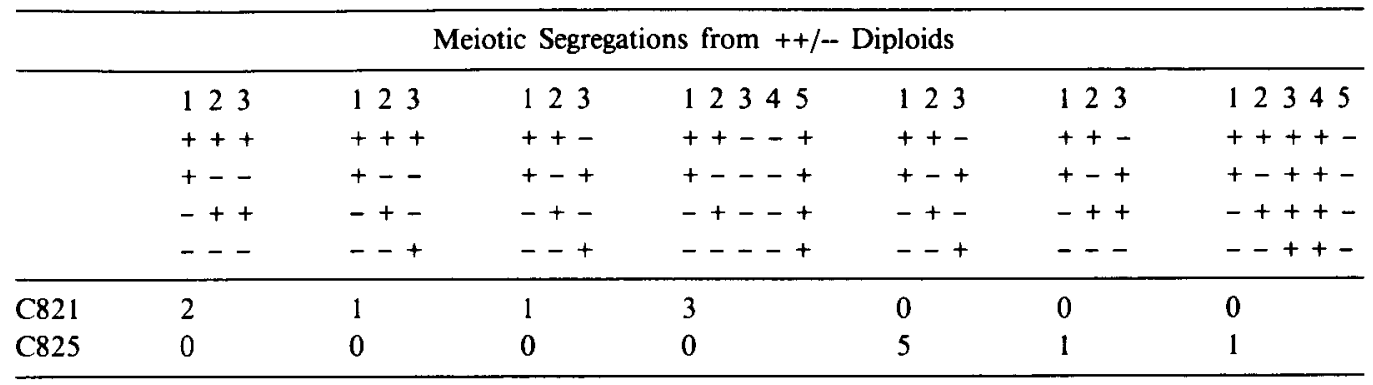

in which the +- and -+ segregants were both cly8, an additional crossover in the $A D E 6$ $C L Y 8$ region involving a third chromatid is required. $A$ fourth ascus, in which the +- and - + segregants are $C L Y 8$ and $c l y 8$, respectively, requires two additional crossovers, a four-strand double in the $A D E 6-C L Y 8$ region. The remain- ing three asci are indeterminate; cly 8 is homozygous in these because of a previous mitotic crossover. In the tetrads from $\mathrm{C} 825$, the + segregants in five asci carried the $C L Y 8$ allele and the - + segregant carried the cly 8 allele. In another ascus, the +- and -+ segregants both carried the $C L Y 8$ allele, as would be expected

\section{Table VIII}

Classes of mitotic prototrophs that are either homozygous for distral markers or carry both proximal and distal mutations at the $A D E 6$ locus. The genotypes are given for the two sites of $A D E 6$ and for $C L Y 8$, in that order, followed by $S U C 1$ and $M A L 1$ (parentheses indicate probable assignment of fermentation markers). Columns 3,4 and 7,8 represent genotypes expected from crossover between sites in $A D E 6$ locus in C819 or C825 and C821, respectively. The expectations are illustrated in the following examples.

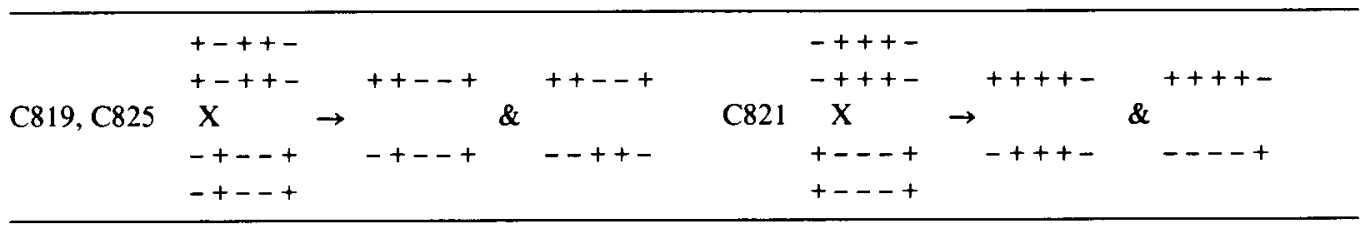

Genotypes of Mitotic Prototrophs

\begin{tabular}{|c|c|c|c|c|c|c|c|c|c|}
\hline $\begin{array}{l}\text { Culture } \\
\text { Number }\end{array}$ & Treatment & 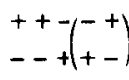 & $\begin{array}{l}++--+ \\
-+--+\end{array}$ & $\begin{array}{l}++--+ \\
---+\end{array}$ & $\begin{array}{l}++--+ \\
+---+\end{array}$ & $\begin{array}{l}+++\left(\begin{array}{l}+ \\
-+\end{array}\right.\end{array}$ & $\mid \begin{array}{l}+++- \\
-+++-\end{array}$ & $\begin{array}{l}+++- \\
--++-\end{array}$ & $\begin{array}{l}+++- \\
+-++-\end{array}$ \\
\hline C 819 & UV & 1 & 4 & 0 & 0 & 0 & 0 & 0 & 1 \\
\hline C825 & $\mathrm{X}$-rays & 5 & 6 & 0 & 1 & 2 & 0 & 0 & 0 \\
\hline \multirow[t]{2}{*}{$\mathrm{C} 825$} & Spont. & 3 & 7 & 3 & 0 & 1 & 0 & 2 & 1 \\
\hline & Totals & 9 & 17 & 3 & 1 & 3 & 0 & 2 & 1 \\
\hline $\mathrm{C} 821$ & $\mathrm{X}$-rays & 1 & 2 & 0 & 1 & 0 & 1 & 0 & 0 \\
\hline C821 & UV & 1 & 1 & 0 & 2 & 2 & 8 & 0 & 2 \\
\hline C821 & EMS & 0 & 1 & 0 & 0 & 0 & 6 & 0 & 0 \\
\hline C821 & Spont. & 0 & 1 & 2 & 3 & 1 & 17 & 0 & 4 \\
\hline \multirow[t]{2}{*}{ C821 } & Spont. & 0 & 0 & 1 & 5 & 3 & 8 & 0 & 2 \\
\hline & Totals & 2 & 5 & 3 & 11 & 6 & 40 & 0 & 8 \\
\hline
\end{tabular}


from a three-strand double crossover, one between the two sites in $A D E 6$, the other in the $A D E 6-C L Y 8$ region. The remaining ascus is indeterminate for the same reason as the three from C821. Since C821 differs from C819 and C825 in the orientation of the alleles at the CLY 8 locus, the results are those expected. No cases of co-conversion were observed, in contrast with what was found at the SUCI MAL1 loci. It is difficult to escape the conclusion that this pattern of segregation is the consequence of double-strand exchange between the two sites, a conclusion that also accounts for the polarity reported earlier in this paper for mitotic recombination at the $A D E 6$ locus (Table I; and in more detail in Table VIII).

\section{CONCLUDING REMARKS}

The purpose of this communication, as stated in the Introduction, was to compare mitotic conversion, both induced and spontaneous, with meiotic conversion in three heteroallelic combinations at the $A D E 6$ locus for evidence of differences that might indicate different mechanisms. The parameters examined were the pattern of recombinational events associated with gene conversion in the three categories and the coincidence of conversion at loci other than $A D E 6$. Aside from the frequencies with which conversion occurred, the observed pattern of recombinant events was similar in induced and spontaneous mitotic conversion and in meiotic conversion. There were quantitative differences, with respect to distal marker recombination, in the induced category among different agents employed. Also, spontaneous conversion showed a distinctly higher frequency of associated recombination than induced conversion. A noteworthy feature of both mitotic and meiotic conversion is the evidence of polarity of distal marker recombination, indicating a sizeable incidence of double-strand breakage between the two sites in $A D E 6$. None of these relationships bears on the validity of any of the models of conversion and associated recombination thus far proposed, including the MESELSONRADDING hypothesis of the mechanism of gene conversion which has served as the commonly accepted working hypothesis (3).

\section{REFERENCES}

1. EsPosito, M.S. \& J.E. WaGsTafF: Mechanisms of mitotic recombination. In: The Molecular Biology of the Yeast Saccharomyces. Life Cycle and Inheritance. J.N. Strathern, E.W. Jones \& J.R. Broach, eds. Cold Spring Harbor, New York pp. 341-370 (1981)

2. FOGEL, S.\& R.K. MORTIMER: Informational transfer in meiotic gene conversion. Genetics 62,96 103 (1969)

3. Meselson, M.S \& C.R. RadDinG: A general model for genetic recombination. Proc. Nat. Acad. Sci. USA 72, 358-361 (1975)

4. ROMAN, H.: Recombination in diploid vegetative cells of Saccharomyces cerevisiae. Carlsberg Res. Commun. 45, $211-224$ (1980), see also ERRATUM 45, p. 423 (1980)

5. Roman, H. \& F. Fabre: Gene conversion and associated reciprocal recombination are separable events in vegetative cells of Saccharomyces cerevisiae. Proc. Nat. Acd. Sci. USA 80, 6912-6916 (1983) 